\title{
O lúdico na inclusão com pessoas com deficiência: uma abordagem transdisciplinar do Turismo
}

\author{
The ludic in the inclusion of people with disabilities: a transdisciplinary approach to \\ Tourism
}

\section{El juguetón en la inclusión con las personas con discapacidad: un enfoque transdisciplinario del Turismo}

\author{
Rita de Cássia dos Reis Viebrantz ${ }^{1}$ \\ Cristiano Hamann ${ }^{2}$ \\ Caroline Casali ${ }^{3}$
}

Este artigo foi recebido em DIA de MÊS de ANO e aprovado em DIA de MÊS de ANO

\begin{abstract}
Resumo:
Diversas formas de saber, tanto provenientes de espaços universitários como de movimentos sociais, têm demonstrado a importância ética e política de programas de inclusão social, em especial nas temáticas relacionadas às pessoas com deficiência (PCD). Neste contexto, tendo em vista o Turismo como campo politicamente estratégico intrinsecamente relacionado às possibilidades de experiência social e exercício de cidadania, objetivouse compreender como ações no campo do Turismo podem proporcionar formas de inclusão com pessoas com deficiência. Para tanto, foi estruturada uma pesquisa intervenção que perfez a criação de um Livro Sensorial, também conhecido como Quiet Book, junto a pessoas com deficiência da Escola de Inclusão, na cidade de Pelotas/RS. Trata-se de um livro lúdico repleto de atividades psicopedagógicas que procura desenvolver aspectos cognitivos e estimular a criatividade e curiosidade. Nesta pesquisa, a produção do livro se deu tendo questões de patrimônio como eixo temático das múltiplas interfaces que o Turismo oferece, demonstrando a possibilidade de elaboração do espaço comum, subjetivamente um lugar estético, ético e político que contradiz lógicas de exclusão. Palavras-chave: Turismo. Inclusão. Pessoas com deficiência. Lúdico. Transdisciplinaridade.
\end{abstract}

\begin{abstract}
:
Diverse forms of knowledge, both from university spaces and from social movements, have demonstrated the ethical and political importance of social inclusion programs, especially in the themes related to people with disabilities $(P C D)$. In this context, in view of Tourism as a politically strategic field intrinsically related to the possibilities of social experience and exercise of citizenship, the objective was to understand how actions in the field of Tourism can provide ways to include People with Disabilities. To do so, a research intervention was structured, which perfected the creation of a Quiet Book with people with disabilities from the School of Inclusion, in Pelotas/RS. It is a playful book full of psychopedagogical activities that seek to develop cognitive aspects and stimulate creativity and curiosity. In this research, the production of the book was done with questions of heritage as the thematic axis of the multiple interfaces that Tourism offers, thefore demonstrating the possibility of elaborating a common space, subjectively an aesthetic, ethical and political place that contradicts logics of exclusion.
\end{abstract}

Keywords: Tourism. Inclusion. Disabled people. Ludic. Transdisciplinarity.

\section{Resumen:}

Diversas formas de conocimiento, tanto de espacios universitarios como de movimientos sociales, han demostrado la importancia ética y política de los programas de inclusión social, especialmente en temas relacionados con las personas con discapacidad (PCD). En este contexto, considerando el turismo como un campo político estratégico intrínsecamente relacionado con las posibilidades de la experiencia social y el ejercicio de la ciudadanía, el

\footnotetext{
Formação/curso: Psicóloga (UCPel). Graduada em Turismo (UFPel). Graduanda em Antropologia (UFPel). Pós-graduanda em Especialização em Práticas Assertivas da Educação Profissional Integrada à Educação de Jovens e Adultos - com Ênfase em Didática (IFRN). Instituição: Professora Tutora na linha do Turismo no Instituto Federal do Sul de Minas - IFSULDEMINAS, Poços de Caldas - MG, Brasil. E-mail: ritaviebrantz2@gmail.com

${ }^{2}$ Formação/curso: Psicólogo e Mestre em Psicologia Social (PUCRS). Doutor em Psicologia Social e Institucional (UFRGS). Instituição: Professor no curso de Psicologia da Escola de Ciências da Saúde e da Vida da Pontifícia Universidade Católica do Rio Grande do Sul - PUCRS, Porto Alegre - RS, Brasil. E-mail: cristiano.hamann@ gmail.com.

${ }^{3}$ Formação/curso: Jornalista (UFSM). Mestre e Doutora em Ciências da Comunicação (UNISINOS). Instituição: Professora no Centro de Ciências Sócio-organizacionais da Universidade Federal de Pelotas - UFPEL, Pelotas - RS, Brasil. E-mail: carolcasali@gmail.com.
} 
objetivo fue entender cómo las acciones en el campo del turismo pueden proporcionar formas de inclusión con las personas con discapacidad. Con este fin, se estructuró una investigación de intervención que condujo a la creación de un Libro sensorial, también conocido como Libro Silencioso, con personas con discapacidad en la Escuela de Inclusión, en la ciudad de Pelotas/RS. Es un libro lleno de actividades psicopedagógicas que busca desarrollar aspectos cognitivos y estimular la creatividad y la curiosidad. En esta investigación, la producción del libro se realizó con cuestiones de patrimonio com la temática de las múltiples interfaces que ofrece el turismo, demostrando la posibilidad de elaborar el espacio común, subjetivamente un lugar estético, ético y político que contradice las lógicas de exclusión.

Palabras clave: Turismo. Inclusión. Personas con discapacidad. Juguetón. Transdisciplinariedad.

\section{Introdução}

O Turismo vem apresentando, historicamente, significativo crescimento e modificações nas suas formas de operar. Caracteriza-se como uma área com múltiplas perspectivas de atuação, sendo redimensionada por possibilidades técnicas que seriam inviáveis décadas atrás, como as facilidades em termos de meios de locomoção (PENA, 2018), tecnologias móveis (DE MASI, 2000) derivadas da Web 2.0 e 3.0, ou de segmentos populacionais mais específicos, como LGBTQI+, jovens, pessoas com deficiência, entre outros (MTUR, 2016a; 2016b; 2017). Considerando essa mudança, o próprio Ministério do Turismo criou cartilhas e diretrizes para atender melhor esses públicos (MTUR 2016a; 2016b; 2017; 2018).

Esses elementos contemporâneos ao Turismo indicam um movimento de criação de nichos de consumo particularizados, que têm sido discutidos por autores(as) de diversos campos teóricos como um movimento global de regionalização e globalização típica do neoliberalismo (MASCARENHAS, 2003). A valorização emergente de certas populações no contexto do Turismo está, neste sentido, muito relacionada à capacidade de compra, o que tem feito pessoas anteriormente silenciadas (por discursos ${ }^{4}$ discriminatórios relacionados à orientação sexual, etnia, classe, território de origem, ou mesmo capacitismo), um alvo estratégico na criação de público consumidor (MTUR, 2017).

$\mathrm{Na}$ esteira dessa discussão, torna-se importante notar que este movimento, observado em nível mundial e caracterizado como de cooptação neoliberal, não deve reduzir as possibilidades do Turismo por vezes tomado exclusivamente como migrações para viagens e lazer, não colocando em pauta a multiplicidade de atuações na área e seu potencial enquanto fazer politicamente estratégico. Verifica-se que as possibilidades na área são muito mais abrangentes e complexas do que a criação de segmentos

\footnotetext{
${ }^{4}$ Neste estudo, a noção de discurso é tomada tal qual indica Foucault (2008), como uma rede de enunciados que compõem formas de conhecer e saber. É constituído historicamente e inscrito socialmente no que o autor chama jogo de verdades - ou seja, na medida que conhecimentos e saberes são históricos e mutáveis, cabendo a nós entender quais são as forças sociais que instauram certas verdades como aceitas em determinado espaço e tempo social (FOUCAULT, 2008).
}

Observatório de Inovação do Turismo - Revista Acadêmica

Vol. XV, $\mathrm{n}^{\circ} 1$, abril - 2021 
de consumo, podendo ser caracterizado como um dispositivo importante no exercício de cidadania (MASCARENHAS, 2005). Tendo em vista essa possibilidade, a questão que se coloca nesta pesquisa é: como o Turismo pode atuar como espaço estratégico para a inclusão social? Busca-se compreender, mais precisamente, como a criação de um Livro Sensorial, tomado como micropolítica e inscrito em uma abordagem lúdica, possibilita formas de inclusão com pessoas com deficiência no contexto de atuação do Turismo.

Considerando esse campo de problematizações, apresenta-se uma pesquisa que se delineou tendo como lócus de análise uma experiência de inserção do projeto de Extensão e Cultura Ludoteca do Turismo (Centro de Ciências Socio-Organizacionais da Universidade Federal de Pelotas/RS) na Associação dos Pais e Amigos de Jovens e Adultos com Deficiência (APAJAD). O Projeto Ludoteca do Turismo foi criado em 2005 e tem como objetivo estudar, elaborar e realizar atividades lúdicopedagógicas a partir de temas relacionados ao Turismo, à Cidadania, ao Patrimônio Histórico e Cultural, ao Meio Ambiente e à Sustentabilidade.

A pesquisa intervenção aqui apresentada se deu a partir da construção de um Livro Sensorial ${ }^{5}$ como artefato psicopedagógico na abordagem do Turismo com pessoas com deficiência. A hipótese de trabalho que guiou esta pesquisa diz respeito ao plano teórico/epistêmico que considera que uma proposta educacional relacionada ao Turismo, pautada em uma abordagem transdisciplinar, pode proporcionar um espaço potencialmente ético, político e estético para o exercício da cidadania e inclusão - já que contradiz uma lógica individualista de subjetividade, capacitista e discriminatória.

\section{Marco teórico}

Pensar o Turismo na perspectiva cidadã é dispor-se a colocar em pauta as diferenças das pessoas enquanto forma de emancipação social. Para que isso aconteça é preciso reconhecer que os sujeitos são biopsicossociais, ou seja, que são uma articulação de elementos indissociáveis em termos biológicos, psicológicos e sociais, e que essas características dizem de necessidades/possibilidades singulares (DE MARCO, 2006). Ter em vista essa compreensão dos sujeitos, e do potencial político do Turismo, é pôr em pauta a criação de estratégias, das quais indica-se duas: que não considerem a pessoa turista sob a égide de um sujeito universal e, portanto, excludente; e que se invista na criação de mecanismos de

\footnotetext{
${ }^{5}$ O Livro Sensorial, também conhecido como Quiet Book, é um livro interativo normalmente feito de feltro, mas que pode ser confeccionado com outros materiais também. Nesse caso, em específico, foi utilizado como base o EVA para diminuir o custo e viabilizar sua distribuição a todos os alunos. É composto por atividades silenciosas e chama-se sensorial porque, através de diferentes sensações, é possível trabalhar diversos aspectos cognitivos, bem como desenvolver o raciocínio lógico, a memória, atenção, concentração e coordenação motora, além de promover a socialização (FELTRO, 2019; MAIS, 2018; OCHOA, 2015; SAÚDE, 2015).
}

Observatório de Inovação do Turismo - Revista Acadêmica

Vol. XV, $\mathrm{n}^{\circ} 1$, abril - 2021 
formação para a cidadania e valorização de si (o que abarca não só a capacidade física e cognitiva, mas o exercício de construção identitária, histórica, social).

Primeiro é preciso desconstruir a prerrogativa de que o público alvo do Turismo é branco, economicamente abastado, heterossexual, eurocentrado e cujo corpo é normativo ${ }^{6}$ o que, pela via do silenciamento, compõem historicamente o estado da arte em grande parte da literatura científica (SEBRAE, 2012; 2017). Esse sujeito universal, discutido no 'estado da arte' pelas formas de dominação que coaduna (CORIOLANO, 2005; MATOS, 2013) demonstra sua falência no campo do Turismo quando se enxerga essa área não simplesmente como um privilégio de uma população específica, mas como possibilidade de exercício de cidadania que transversaliza as formas de ser e estar no mundo pela via da diferença.

Em segundo, essa valorização da diferença exige que se amplifique as possibilidades do Turismo para além do que seriam as necessidades de lazer e viagens de um público abastado economicamente. O Turismo, neste sentido, possibilitaria uma relação política, ética e estética quando insere como de seus fazeres a valorização regional, a ocupação ecologicamente consciente dos territórios, a memória e o patrimônio pela construção de espaços comuns - territórios subjetivos que contradizem lógicas de exclusão pois aproximam pessoas diferentes em prol de relações de afecção e sensibilidade (CAMARGO, 2017). Esse espaço de compartilhamento - tomado enquanto lugar de encontro entre as pessoas a partir de suas singularidades (de gênero, sexualidade, raça/etnia, deficiência, território etc.) pode se dar em processos tomados pela via de atividades do campo educativo.

Conforme Saviani (2013), a educação "institui”" a humanidade, pois:

\begin{abstract}
A educação é entendida como instrumento, como um meio, como uma via através da qual o homem se torna plenamente homem apropriando-se da cultura, isto é, a produção humana historicamente acumulada. Nesses termos, a educação fará a mediação entre o homem e a ética permitindo ao homem assumir consciência da dimensão ética de sua existência com todas as implicações desse fato para a sua vida em sociedade. Fará, também, a mediação entre o homem e a cidadania, permitindolhe adquirir consciência de seus direitos e deveres diante dos outros e de toda a sociedade... Em outros termos, pela mediação da educação, será possível construir uma cidadania ética e, igualmente uma ética cidadã. (SAVIANI, 2013, p. 1).
\end{abstract}

A despeito da possível crítica ao uso do termo "homem" como indicativo de um ser universal, que aqui compreende-se como falho pois não problematiza diferenças como as de gênero, sexualidade,

\footnotetext{
${ }^{6}$ Norma, em Foucault (1987), decorre do poder disciplinar, hegemônico na modernidade e presente na contemporaneidade. Figura para o autor sob a forma de processos de normalização social, que são maneiras de enquadramento dos sujeitos em regras sociais pela via da inscrição de uma ideia de normalidade. É importante destacar que esses processos se dão, muitas vezes, pelo silenciamento de uma faceta da vida. Não discutir as diferenças corporais e cognitivas, por exemplo, é basear-se na noção de que só existe um corpo que vale a pena ser vivido - o que se enquadra como uma faceta de produção das lógicas capacitistas.
}

Observatório de Inovação do Turismo - Revista Acadêmica

Vol. XV, $\mathrm{n}^{\circ} 1$, abril - 2021 
raça/etnia, território, que se localizam na própria história do que se entende enquanto cidadania, apreende-se como importante tal posição produtiva (e não simplesmente reprodutiva) da educação na constituição de sujeitos. Esse processo, entretanto, ocorre repleto de conflitos. Conforme Santos (1987, p. 7 apud BRZEZINSKI; SANTOS, 2015, p. 14), "no campo da retórica, o conceito de cidadania é um dos mais proclamados, anunciados e prometidos, mas, no campo dos fatos, é também um dos mais negligenciados". Considera-se que essa disparidade pode se dar justamente no elencar da cidadania pela via da igualdade (todos somos iguais) e não da diferença e equidade (somos diferentes e, portanto, precisamos de intervenções sociais singulares) dificulta a efetividade das políticas de inclusão no cotidiano.

Neste sentido, Mantoan (2004, p. 7-8), referindo-se a inclusão por intermédio da educação, afirma que "há diferenças e há igualdades, e nem tudo deve ser igual nem tudo deve ser diferente, [...] é preciso que tenhamos o direito de ser diferente quando a igualdade nos descaracteriza e o direito de ser iguais quando a diferença nos inferioriza". Essa postura (aqui denominada ética, política e estética), pode se expressar em diversas ações. A crescente valorização das diferentes formas de cultura para além das europeias, bem como estudos científicos de cunho social que valorizam as diferenças, por exemplo, têm incluído múltiplas abordagens em diversificados segmentos do Turismo (MOREIRA, 2010).

Neste contexto de discussão, sendo o conceito contemporâneo de cidadania ligado diretamente à dignidade e condição de acesso aos direitos sociais (LIMA et al., 2017), onde todos, teoricamente, são iguais perante a lei (mas diferentes na vida cotidiana), poderá reconhecer-se no Turismo e suas múltiplas atuações muitas formas do exercício da cidadania e inclusão. Considera-se que uma importante estratégia de constituição cidadã é o foco nas questões relativas ao patrimônio (resultados de exercícios históricos e sociais) e a valorização das experiências coletivas expressas a partir deles. Nesse sentido, entende-se que questões referentes ao patrimônio no Turismo podem coadunar ações em prol da produção de identidade e memória, interseccionando educação patrimonial e atratividade turística, de forma a constituir-se como um partido micropolítico para a promoção da cidadania. Aqui, tais ações podem ser consideradas pequenas, localizadas em grupos, comunidades e territórios, entretanto, são potentes politicamente para produzir subjetividades libertárias. Como indica Soares (2016), para que a contemporaneidade possa se firmar como "um novo momento de insurgência dos poderes da multidão, [...] que a atitude por excelência é a do militante que resiste criativamente ao comando imperial na produção de novos modos de ser e estar no mundo, num movimento incessante de contágio." (SOARES, 2016, p. 126).

Considera-se como possibilidades estratégicas de trabalho, nesta linha de raciocínio, aquelas que se compõem numa abordagem transdisciplinar, ou seja, que transversalizam uma série de 
conhecimentos teóricos tendo por potencial um fazer compartilhado e não hierárquico (DOMINGUES, 2001). Compreende-se ser esta uma proposição para o exercício do Turismo - que pode investir no potencial transgressor dos eventos cotidianos, ou seja, na sua potência de transformação social (GUATTARI; ROLNIK, 2006). Assim, "é preciso que cada um se afirme na posição singular que ocupa; a faça viver, que a articule com outros processos de singularização e que resista a todos os empreendimentos de nivelação de subjetividade" (GUATTARI; ROLNIK, 2006, p. 50). Essa nivelação é entendida como uma afirmação identitária rígida, repleta de especificações excludentes, pois são muito calcadas numa ideia de normal/anormal e não permitem que as pessoas se afetem com a presença e singularidade das outras. Procura-se, neste estudo, indicar como é possível um outro movimento, de criação de espaços comuns, em que normativas capacitistas (já que o alvo deste trabalho é atuar com pessoas com deficiência) possam ser abandonadas em prol de encontros que valorizem a diferença enquanto potência.

Dessa forma, em relação às pessoas com deficiência, é preciso considerar uma noção biopsicossocial, ou seja, as confluências que - didaticamente separadas - se entendem como: biológicas (corporais, genéticas), psicológicas (comportamento, personalidade) e sociais (familiares, socioeconômicos, culturais). Assim, numa abordagem transdisciplinar que contemple as necessidades pela via das singularidades, essa pesquisa visa responder de que maneira o Turismo pode atuar como espaço estratégico para a inclusão social. Compreende-se que, nesse processo, e considerando a diferença das pessoas que compõem espaços educacionais, as atividades lúdicas podem contribuir como ferramenta de inclusão com pessoas com deficiência. Neste sentido - pensando formas possíveis para promover espaços de inclusão que ofereçam uma abordagem singular e dinâmica, contemplando as diferenciadas necessidades das pessoas - apresenta-se, a seguir, os procedimentos adotados na realização da pesquisa intervenção.

\section{Metodologia para uma pesquisa intervenção em Turismo}

Este estudo se caracteriza como pesquisa intervenção, que "amplia as bases teóricometodológicas das pesquisas participativas, enquanto proposta de atuação transformadora da realidade sócio-política, já que propõe uma intervenção de ordem micropolítica na experiência social" (ROCHA; AGUIAR, 2003, p. 67).

O local escolhido para elaboração da pesquisa intervenção foi a Escola da Inclusão da Universidade Federal de Pelotas, um dos espaços de ação do Projeto Ludoteca do Turismo. A Escola da Inclusão atende adolescentes e adultos com idades variadas, que possuem diferentes necessidades 
intelectuais e físicas, relacionadas à visão, audição, fala, locomoção e coordenação motora grossa, geral, específica e fina ${ }^{7}$. No segundo semestre de 2018, quando a pesquisa foi realizada, a Escola da Inclusão atendia um grupo de 17 alunos(as) regularmente matriculados(as) e assíduos(as), formado por jovens e adultos com idades que variavam entre 24 e 58 anos.

As ações de intervenção foram realizadas por uma participante do Projeto Ludoteca do Turismo (doravante pesquisadora), a partir de sete encontros e duas saídas de campo com esse grupo (de interlocutores e interlocutoras), na presença da professora responsável. Como técnica de pesquisa optouse pelos registros oriundos da etnografia, que visa a descrição densa e crítica de aspectos singulares das sociedades. A etnografia não se propõe a desvendar relações causais do fenômeno olhado, mas busca a natureza processual, as formas como as relações são construídas em particular ou nas interações interpessoais desenvolvidas no âmbito social (MATTOS, 2011).

Tendo em vista a preocupação com essa processualidade, a presente investigação alicerçou-se em uma interação ativa e dinâmica entre pesquisadora e interlocutores(as), estimulando a reflexão sobre a ação em si e atentando em uma análise holística das situações vivenciadas. Mattos (2011, p. 51) afirma que, nesse contexto, "o sujeito da pesquisa, historicamente ator das ações sociais e interacionais, contribui para significar o universo pesquisado exigindo a constante reflexão e reestruturação do processo de questionamento do pesquisador". Para tanto, utilizou-se da construção de um Diário de Cenas, também conhecido como Diário de Campo ou Diário de Pesquisa, fundamental para a contextualização, entendimento e interpretação das vivências, no qual foram descritos os comportamentos manifestados, percepções e interações do contexto inserido. Algumas observações registradas nesse Diário de Cenas são apresentadas nos resultados da pesquisa como parte importante da análise.

A pesquisa intervenção contou com um primeiro momento em que foi organizado o calendário de atividades e foram agendadas saídas de campo e reuniões de orientação e supervisão. Inicialmente houve um primeiro contato da pesquisadora com interlocutores(as) para familiarização com a turma, o que proporcionou um maior conhecimento acerca de suas peculiaridades e formas de comunicação, base para o planejamento das atividades a serem realizadas durante o trabalho.

\footnotetext{
${ }^{7}$ Por possibilitar um desenvolvimento sensorial, cognitivo e motor, o Livro pode ser indicado para pessoas com deficiência visual, auditiva e motora parcial ou moderada, paralisia cerebral, Síndrome de Down e TEA Transtorno do Espectro Autista (características abarcadas no grupo desta pesquisa). Ainda assim, outras necessidades podem ser contempladas, como a de pessoas cegas, surdas ou com dificuldades motoras e cognitivas mais severas, desde que a atividade seja elaborada conforme a exigência do perfil almejado. Por exemplo, uma pessoa cega poderá realizar a atividade "quebra-cabeça da Praia do Laranjal" se a figura a ser montada apresentar uma sensibilidade tátil (contorno do desenho com cola em relevo). O processo interventivo dependerá do sujeito ou grupo a ser contemplado, da sensibilidade, criatividade e habilidades da equipe que irá planejar as atividades.
}

Observatório de Inovação do Turismo - Revista Acadêmica

Vol. XV, $\mathrm{n}^{\circ} 1$, abril - 2021 
Foi realizada também uma pesquisa bibliográfica de material midiático e sites de educação em busca das atividades mais adequadas a serem utilizadas, pensando na melhor forma de adaptação a um grupo bastante diferenciado entre si. A partir dessa pesquisa, optou-se pela utilização do Livro Sensorial, Quiet Book, que é um livro normalmente feito de feltro ou pano, mas que pode ser confeccionado com outros materiais. Nesse caso, em específico, foi utilizado como base o EVA, material resultante da mistura de etil, vinil e acetato, comum em artesanato, para diminuir o custo e viabilizar sua distribuição a todos os alunos ${ }^{8}$. O Livro Sensorial pode ser composto por histórias, apenas imagens ou mesmo atividades pedagógicas direcionadas, como aprendizagem das horas, contagem de números, bem como cálculos simplificados, por exemplo. É composto por atividades silenciosas e chama-se sensorial pois, através de diferentes sensações experimentadas, é possível trabalhar diversos aspectos cognitivos, desenvolver o raciocínio lógico, a memória, atenção, concentração, coordenação motora etc.

Conforme Ochoa (2015, p. 52-53), o Livro Sensorial auxilia no desenvolvimento motor e cognitivo através de sua capacidade de interação tátil, visual e sensorial. O Livro Sensorial, como instrumento psicopedagógico, pode ser considerado um elemento artesanal e educativo de caráter didático, que estimula a criatividade, desperta a curiosidade e respeita diferentes potencialidades cognitivas. Além disso é um material que, ao final das atividades, pode ser levado para casa e ser reutilizado inúmeras vezes, inclusive por familiares, pois trata-se de um brinquedo educativo. Considerando que o grupo se caracterizava por ser constituído por famílias com diferentes situações socioeconômicas, outra adição oferecida foi a possibilidade de ofertar gratuitamente um instrumento de extremo valor psicopedagógico. Um Livro Sensorial pode custar até $\mathrm{R} \$ 395,00,{ }^{9}$ dependendo de sua complexidade (ELO7, 2018; MERCADO LIVRE, 2018), o que inviabilizaria sua aquisição para muitas famílias.

As atividades trabalhadas a partir do Livro Sensorial tiveram como foco o Turismo - Patrimônio Histórico, Cultural, Natural, Material e Imaterial. Foram realizados nove encontros de trabalho entre pesquisadora e interlocutores(as) e as atividades realizadas nestes encontros são descritas a seguir.

\section{Resultados de uma intervenção transdisciplinar em Turismo}

Vejo pela primeira vez a turma da Escola da Inclusão e me surpreendo. É bastante heterogênea e percebo como um grande desafio, o que torna essa experiência ainda mais atrativa para mim. A recepção foi feita repleta de ternura e muito afeto, recheada

\footnotetext{
${ }^{8}$ No que concerne ao material do Livro Sensorial desenvolvido, considera-se importante notar a necessidade de um estudo para compreender alternativas ambientalmente e economicamente mais sustentáveis (reutilizados, reciclados ou de origem natural). Confluindo, nesse aspecto, para uma leitura capilarizada em termos das aproximações potentes entre Turismo e discussões do campo da educação e sustentabilidade.

${ }^{9}$ Valores de 2018.
}

Observatório de Inovação do Turismo - Revista Acadêmica

Vol. XV, $\mathrm{n}^{\circ} 1$, abril - 2021 
de abraços carinhosos e aconchegantes. Me senti muito feliz e tive a certeza que havia tomado a decisão correta em relação ao trabalho. Tranquilamente observo cada um e lentamente vou me aproximando e interagindo, um de cada vez. Alguns ainda estão um pouco receosos diante uma presença estranha em sala de aula, outros prontamente me chamam e se aproximam. Entretanto, em momento algum houve qualquer hostilidade, somente um breve e leve estranhamento e timidez inicial. (DIÁRIO DE CENAS, 2018, p. 1).

Todo o processo de vivência anterior a criação do Livro Sensorial deu subsídios para uma aproximação e construção de relações entre pesquisadora e interlocutores. O primeiro encontro efetivo de atividades iniciou com um trabalho focado em algo que havia sido vivenciado recentemente pelo grupo, o período de férias. A partir desse tema, foi possível aproveitar vivências prévias do grupo e compreender particularidades relacionadas a interesses ou mesmo ao processo de comunicação (quais aspectos seriam interessantes potencializar em termos de aprendizado e experiência coletiva). Foi proposto que os interlocutores realizassem desenhos das atividades de lazer efetivadas durante o período de férias; depois disso, houve a montagem coletiva de um painel com os desenhos realizados, procurando compreender como o grupo conseguia interagir e trabalhar em equipe. $\mathrm{O}$ material foi, posteriormente, fixado para exposição em sala de aula e valorização das construções desenvolvidas conjuntamente. Através de observação e interação, foi verificada a necessidade de trabalhos futuros que envolvessem principalmente a percepção visual, constatada como principal figura de comunicação. Também foi apurada a necessidade de constante repetição dos eixos temáticos a serem trabalhados, como forma de fixação.

Na segunda intervenção, iniciou-se a confecção do Livro Sensorial, com o acordo de que o Livro fosse desenvolvido em vários encontros, subdivididos por temáticas elencadas em conjunto com a turma. Nesse aspecto os interesses do grupo seriam trabalhados conjuntamente. Esse momento foi estratégico pois considerar a adesão a atividade era um elemento indispensável para uma relação interpessoal produtiva e motivação adequada.

Ao longo do período de trabalho, foi possível observar que diversos(as) integrantes do grupo eram notadamente ativos(as) em relação as questões tradicionais do Rio Grande do Sul, como participação em Centros de Tradições Gaúchas (CTGs) e afins. Tendo em vista essa relação com aspectos da cultura gaúcha, procurou-se elaborar um processo de trabalho relacionado. Houve a apresentação de slides sobre a Revolução Farroupilha com uma breve introdução ao conceito de Patrimônio e, após atividades relacionadas ao mesmo tema com pintura, recorte e montagem de material previamente preparado em papel (gaúcho e prenda tomando chimarrão), realizou-se também uma oficina de chimarrão. No Livro Sensorial foi abordado o tema da Semana Farroupilha, na qual estudantes o experimentaram pela primeira vez, realizando atividades como: montagem de uma cuia de chimarrão e 
de vestimenta gaúcho e prenda (Figura 1 - Gaúcho e Prenda) e conhecimento da lenda do pampa gaúcho do Quero-quero. Nesse momento, o tema referente à Semana Farroupilha foi escolhido por tratar-se de um elo com o grupo familiar, que se mostrava bastante presente e ativo.

Figura 1. Primeira atividade do livro sensorial, ilustração da prenda e do gaúcho e da cuia de chimarrão.

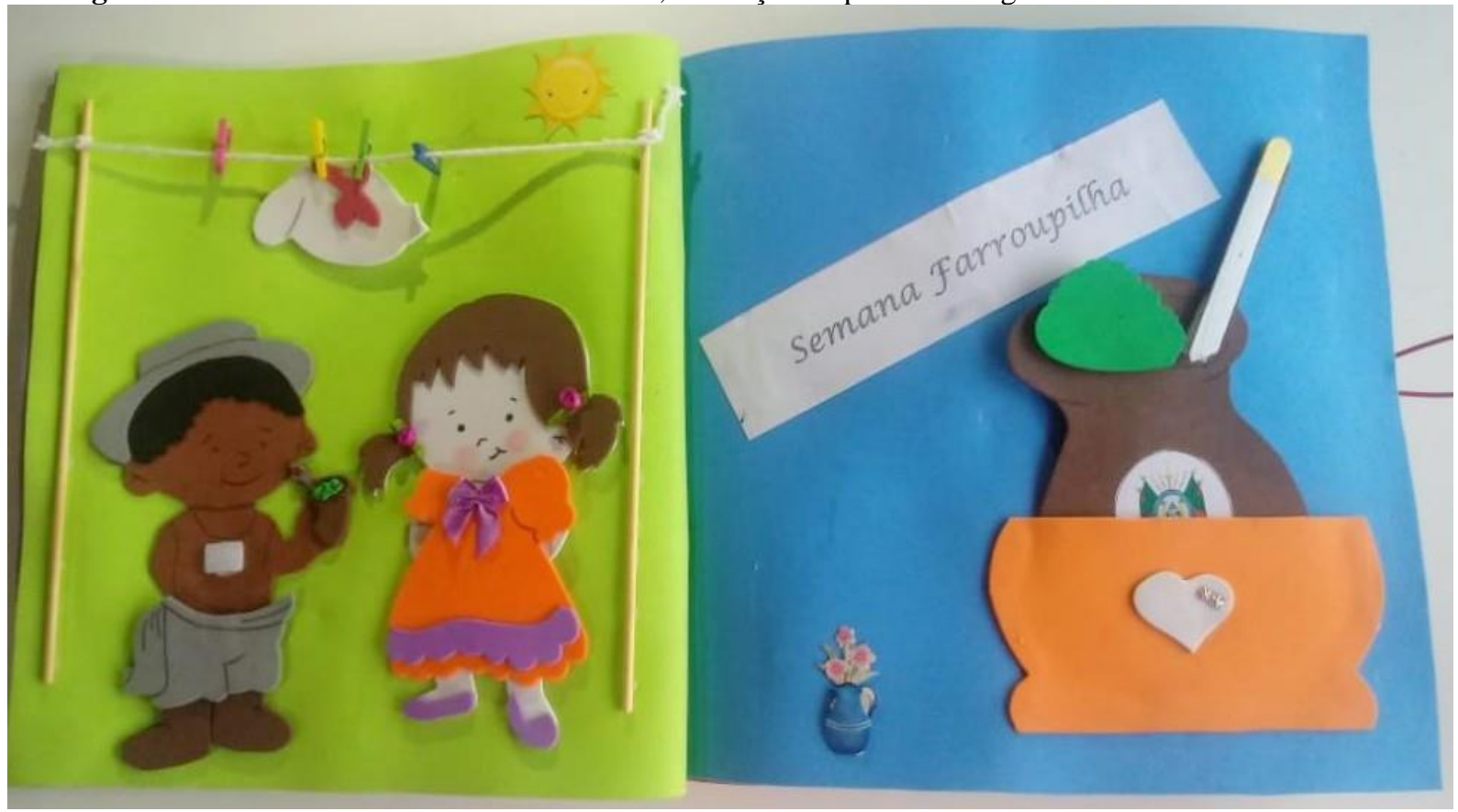

Fonte: Acervo Ludoteca UFPel (2018).

Concomitante a essas questões, foram trabalhadas atividades que desenvolvessem a percepção das cores: vermelho, azul, amarelo e verde e conceitos de maior/menor, em cima/embaixo, grande/pequeno e motricidade grossa, bem como o sentimento de pertencimento. Sempre que possível, eram acrescentadas às atividades itens (cores ou imagens representativas) que estimulassem o engajamento de estudantes e que pudessem facilmente ser perceptíveis a todos.

A terceira intervenção incluiu a apresentação de slides sobre o tema Primavera e Patrimônio Natural. Na continuação da elaboração do Livro, foram exercitadas questões relativas à natureza, além de reforço do sentimento de pertencimento em relação à praia do Laranjal (Figura 2: Laranjal). A praia do Laranjal é uma praia banhada pela Lagoa dos Patos, situada a dez minutos do centro da cidade de Pelotas/RS, no estado do Rio Grande do Sul. É um importante atrativo turístico do município de Pelotas, onde residem estudantes do grupo. 
Figura 2. Segunda atividade do Livro Sensorial, quebra-cabeças da praia do Laranjal.

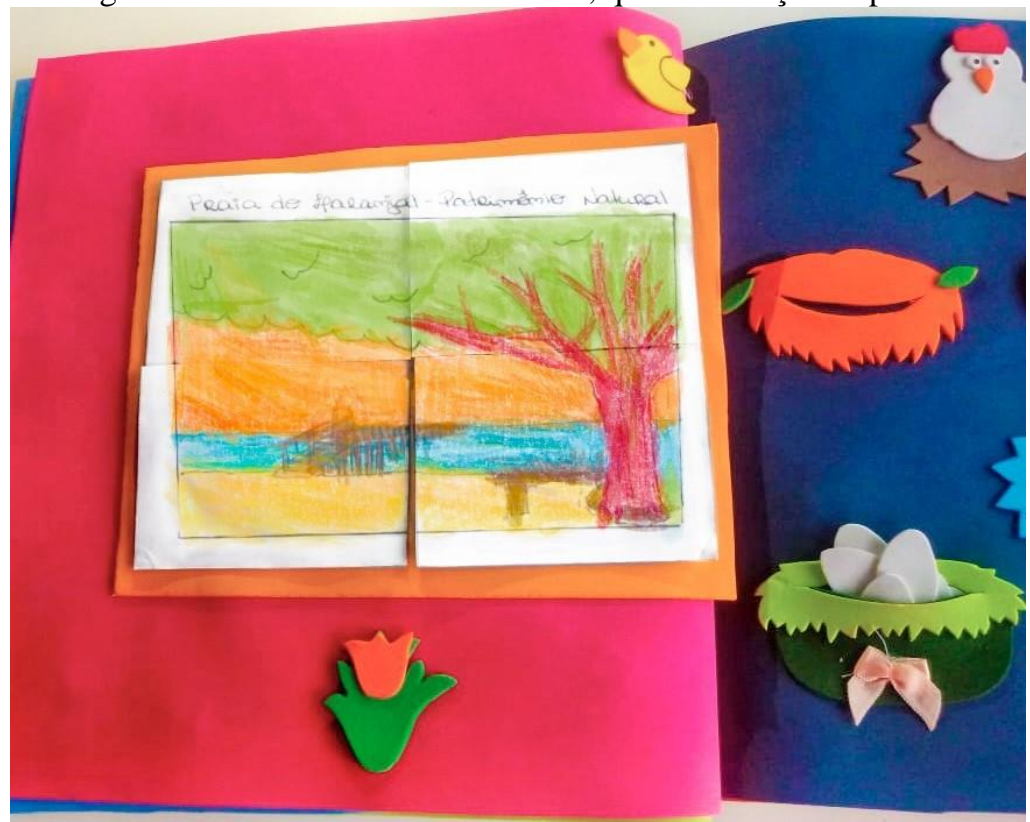

Fonte: Acervo Ludoteca UFPel (2018)

Todo o processo de confecção do Livro Sensorial ocorreu de forma espontânea, sendo alguns aspectos continuamente repensados e adaptados conforme exigia a demanda. Nesse aspecto, a abordagem da Primavera permitiu uma concepção ampla envolta em cores, condizente com o tema e atrativa para o grupo de estudantes. Na continuidade das estratégias de elaboração, a atividade relacionada à praia do Laranjal em formato de um quebra-cabeça simplificado facilitou sua montagem, mesmo ao grupo de interlocutores(as) com condições de baixa visão.

Lentamente aprendi a reconhecer as limitações, birras e brilho de cada um. A comunicação acontecia mais por instinto do que por técnica. A verdade é que, para compreender a mensagem, um olhar, um sorriso ou um simples afago é tão ou mais eficaz que a palavra propriamente falada. Dia após dia sentia a proximidade crescente com o grupo e o avanço em relação aos objetivos inicialmente propostos. Cada tema proposto exigia um reforço visual e a constante retomada toda semana, já que o aprendizado do grupo se dava, principalmente, por intermédio de imagens. Sendo assim, tornou-se essencial criar materiais atrativos para facilitar a fixação. Dessa forma, a intervenção ficou cada vez mais "colorida" e confesso que me divertia e me realizava com cada atividade pensada e previamente preparada. (DIÁRIO DE CENAS, 2018, p. 4).

Assim, a adequação das tarefas propostas se desenvolvia conforme a percepção das dificuldades singulares apresentadas pelos(as) estudantes. Essa postura precisava ser sempre redimensionada, para tornar possível não somente a compreensão dos enunciados, mas propiciar sua real realização.

Observatório de Inovação do Turismo - Revista Acadêmica

Vol. XV, $\mathrm{n}^{\circ} 1$, abril - 2021 
Na quarta intervenção, ocorreu a apresentação de slides sobre Turismo Rural, uma preparação para as futuras saídas de campo para Capão do Leão/RS, município vizinho de Pelotas/RS onde se localiza a Fazenda da Palma - centro agropecuário que é administrado pela Universidade Federal de Pelotas.

Nessa intervenção foram realizadas atividades relacionadas ao tema proposto como pintura e recorte em papel (alimentos, animais diversos, animais domésticos e de fazenda). Os animais pintados em papel foram posteriormente colados em EVA para incluir no Livro. Essas atividades de pintura e colagem possibilitaram a percepção de animais rurais e domésticos, aspectos relacionados à vida no campo, percepção do dia e noite, de aberto e fechado, de dentro e fora, vazio e cheio, perto e longe, na frente e atrás, localização espacial, familiarização com números e contagem, bem como coordenação motora fina e grossa.

$\mathrm{Na}$ abordagem em Turismo Rural, a escolha deu-se por atividades que atuassem de forma a contemplar, dentre outros aspectos, o desenvolvimento da autonomia do grupo de estudantes. Sempre respeitando suas singularidades e ritmo, diversificadas tarefas eram cuidadosamente pensadas e criadas de forma a beneficiar sua compreensão, facilitar e estimular o lúdico, relacionando Turismo e questões educativas.

Desde o primeiro contato, minha principal percepção além da heterogeneidade do grupo, foi a colaboração constante entre os membros. As dificuldades são diversas, entretanto a cooperação entre eles(as) não passa desapercebida, aqueles(as) que possuem maior independência, assim que finalizadas as tarefas, ajudam colegas no término, com a mesma disposição que realizaram as próprias atividades, seja pintura, cola ou recorte. Perfeitamente engajados(as), transmitem as instruções com a mesma simplicidade que a compreenderam. São pessoas admiráveis, possuidoras de qualidades como generosidade, tão evidentes que me fizeram questionar o quanto a humanidade perde ao evitar um envolvimento, simplesmente por preconceito ou até mesmo "medo" de não saber como agir. Não há uma receita. Quando respeitamos nosso semelhante com sinceridade, o fato é que nós é que somos beneficiados com essa relação. (DIÁRIO DE CENAS, 2018, p. 1-2).

A devotada colaboração era constantemente percebida e refletida nas ações de cooperação entre participantes das intervenções. Alguns careciam de uma maior atenção, devido a evidentes limitações físicas mais proeminentes. Dessa forma, diversas atividades eram previamente preparadas de forma a facilitar sua realização, mesmo com a necessidade de algum auxílio. Nesse aspecto, a valorização do auxílio verificado na dinâmica do grupo, bem como o reconhecimento e respeito das diferenças e limitações individuais vêm ao encontro de um fazer compartilhado que se diferencia da racionalidade do mundo competitivo neoliberal. 
No quinto encontro, foi realizada uma saída de campo com estudantes e familiares para conhecer o Projeto Pet Terapia do curso de Medicina Veterinária no Campus da Universidade Federal de Pelotas no município de Capão do Leão/RS. Lá foram realizadas diversas atividades com os cães treinados e, depois, um piquenique de confraternização. $\mathrm{O}$ encontro foi benéfico a todos(as) envolvidos(as) alcançando êxito em relação à proposta almejada que era não só de valorizar a vivência do grupo, mas também de envolver os núcleos familiares na construção do projeto. Esse envolvimento familiar, bem como da comunidade e da rede social, torna-se sumamente importante no sentido de permitir a interação no processo de inclusão.

No sexto encontro, houve a apresentação de slides sobre Patrimônio (focado em Festas e Eventos) e retomada do conceito geral do mesmo. Em seguida, ocorreu a realização de atividades pertinentes com o tema de Halloween, como pintura e recorte em papel (caveiras mexicanas). $\mathrm{Na}$ continuidade dos trabalhos, certas adequações tornaram-se necessárias, como a diminuição da utilização de velcro nas atividades e a preferência por materiais mais resistentes e de fácil manuseio, como simples sobreposição ou encaixe.

No encontro seguinte, foi realizada uma visita para conhecer os trabalhos realizados na Fazenda da Palma com estudantes e familiares da Escola da Inclusão. Nessa saída de campo (sétima intervenção) foram efetivadas atividades com os animais da fazenda (ovelhas, cavalos, potro, bezerro), previamente planejadas e onde interlocutores(as) tiveram a oportunidade de experimentar contato mais intenso com elementos da natureza. $\mathrm{Na}$ continuidade, houve um piquenique de integração com todos(as) envolvidos(as).

A oitava intervenção focou o Patrimônio Histórico e Cultural da cidade de Pelotas. Foram realizadas atividades de recorte e colagem de imagens de prédios que compõem o entorno da praça principal da cidade, para reforçar o sentimento de pertencimento, valorização do patrimônio histórico e reconhecimento de alguns pontos turísticos da cidade de Pelotas/RS: Mercado Central, Casarões, Grande Hotel, Praça Coronel Pedro Osório, Chafariz, Prefeitura Municipal de Pelotas, Biblioteca Pública e Theatro Guarani. O Livro Sensorial também trabalhou esses aspectos da percepção e sentimento de pertencimento, além da aprendizagem das horas (Figura 4 - Mercado Público). 
Figura 3. Quinta atividade do Livro Sensorial, ilustração do Mercado Central da cidade de Pelotas/RS.

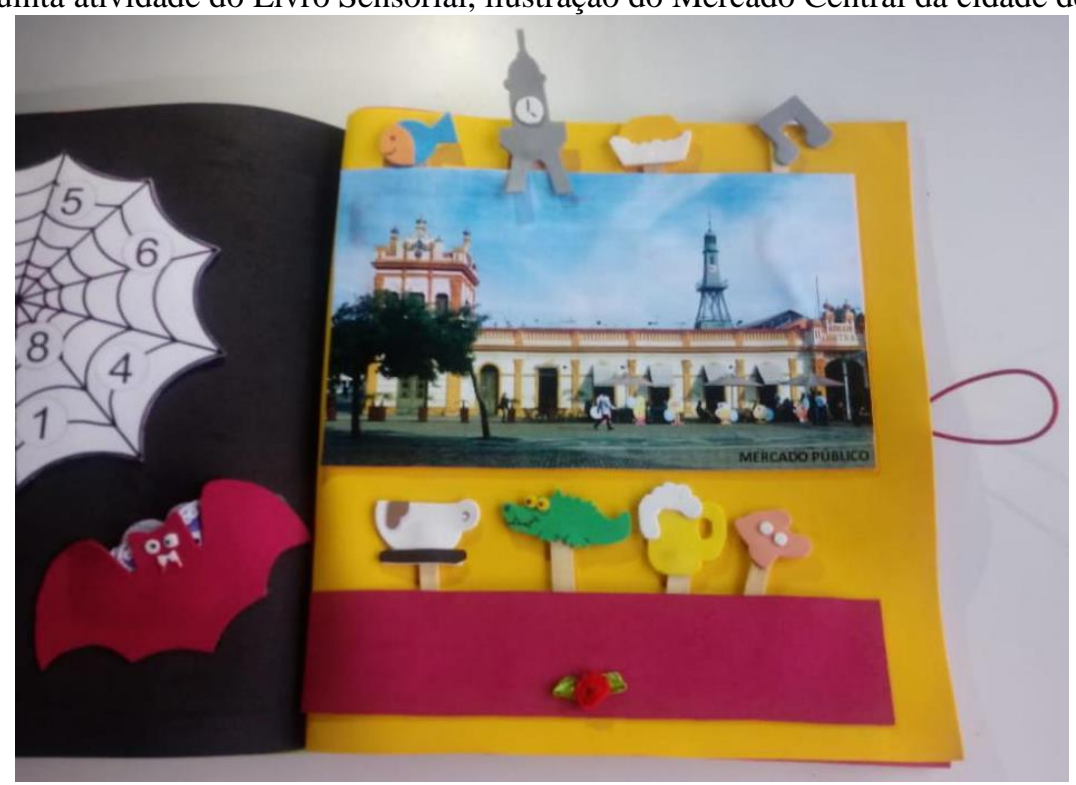

Fonte: Acervo Ludoteca UFPel, 2018.

O Livro Sensorial foi produzido com grande expectativa e dedicação no decorrer dos trabalhos. Algumas atividades eram feitas em sala de aula e anexadas posteriormente, mas a cada encontro eram construídas uma ou mais páginas que seriam reunidas e entregues no último encontro. (DIÁRIO DE CENAS, 2018, p. 3).

Na nona e última intervenção, houve a apresentação de um vídeo com recordações dos principais momentos vivenciados no decorrer do semestre, seguido pela elaboração da capa personalizada do Livro Sensorial, com a utilização de materiais para decoração previamente solicitados para o grupo, bem como uma foto pessoal para identificação. Foi então realizada a finalização e entrega do mesmo a cada estudante. Por fim, para o encerramento, ocorreu a entrega dos certificados de conclusão do Projeto Ludoteca - Escola da Inclusão.

A entrega dos certificados tornou-se extremamente significativa em razão da grande expectativa gerada em torno do encontro final e da construção personalizada de sua capa. Era o momento final da "formatura" (assim nomeado pelo próprio grupo), onde o desempenho pessoal de cada um seria reconhecido e aprovado.

\section{Conclusões sobre uma intervenção transdisciplinar em Turismo}

No presente trabalho foi possível compreender como a criação de um Livro Sensorial, tomado como micropolítica e inscrito em uma abordagem lúdica, possibilita formas de inclusão com pessoas com deficiência no contexto de atuação do Turismo. Dessa forma, conteúdos e atividades relacionadas

Observatório de Inovação do Turismo - Revista Acadêmica

Vol. XV, $\mathrm{n}^{\circ} 1$, abril - 2021 
ao Turismo de forma transdisciplinar, tendo como eixo de produção questões de patrimônio, contribuem de forma concreta em ações de inclusão com pessoas com deficiência.

Durante todo o processo da realização da pesquisa, desde o pensar e o encontro inicial, foi percebido o imenso desafio que seria a realização de atividades que contemplassem um público com características singulares. Entretanto, no transcorrer do procedimento e com a constatação da cooperação mútua e grande senso de engajamento, todo o trabalho evoluiu de forma gradual e contínua, sempre adequando-se a novas propostas (realizadas conforme sentidos e significados construídos com o grupo).

No processo de pesquisa intervenção foi plausível a importante necessidade de uma preparação prévia e contextualizada, o que envolve compreender as diferenças não como limitações, mas como formas de investimento em potenciais (cognitivos, físicos, sociais). Considerando essa postura, foi possível colocar em pauta diversificadas possibilidades de atuação em conteúdos referentes ao Turismo, através das questões que remetem especialmente ao eixo temático Patrimônio. Em especial, considerase que foi importante o investimento numa abordagem lúdica com a elaboração conjunta de um Livro Sensorial, já que permitiu a construção de um espaço comum transdisciplinar. Trata-se, subjetivamente, de um lugar ético, estético e político que contradiz lógicas de exclusão - pois produz a experiência de fazer uma atividade protagonizada pelos(as) alunos(as) numa relação não hierarquizada com a pesquisadora-interventora, o que destoa das atribuições históricas de exclusão e reclusão destas pessoas, envolvendo afetos e sensibilidades outras.

Nessa experiência pude compreender dimensões que encontram-se além da imagem simplificada do que é considerado "normal e aceitável" dentro de padrões e regras sociais impostas. Tive o privilégio de conhecer e conviver com pessoas incríveis que muito mais me ensinaram do que eu fui capaz de informar, sendo assim abraçada na alma para sempre. Sem exigências, sem obrigações, sem medos. Descobri que o afeto se espalha por osmose. (DIÁRIO DE CENAS, 2018, p. 6).

Um aspecto importante a ser considerado foi o fato da existência de pouco material referente a utilização e elaboração de um Livro Sensorial, especialmente trabalhos científicos em relação ao mesmo, encontrado principalmente em sites informais educacionais e/ou pedagógicos, tutoriais no YouTube, blogs pessoais ou canais de vendas artesanais e profissionais, evidenciando a oportunidade de estudos mais detalhados e aprofundados.

Outro fator relevante observado foi a ocorrência de que a inclusão com PCD permanece bastante mascarada na presença da família, ou seja, o seio familiar ainda é o principal meio de convivência do grupo, bem como daqueles que se encontram em similar situação, constituindo-se de pequenos círculos de amizades. Mesmo quando são criadas iniciativas de inclusão, as mesmas ainda permanecem cerceadas, quase exclusivamente, por esses pequenos grupos. Essa constatação reforça a importância da 
coexistência, possível por intermédio do Turismo, de diferentes interações com as comunidades em geral no intuito de ampliar essa convivência e, dessa forma, poder trabalhar com a inclusão.

Considera-se que uma intervenção no Turismo (com foco na diferença), em especial PCD, não opera pela via da padronização, ou se sustenta numa noção de sujeito universal, podendo, nesse sentido, atuar efetivamente na inclusão. Analisando que o exercício de cidadania coaduna tanto formas de compartilhar saberes (conhecimentos formais e informais que têm caráter psicopedagógico) como a possibilidade de construir experiências sociais (compartilhamento de temáticas como patrimônio, conhecimento sobre o espaço urbano, identidade e pertencimento social), alguns elementos mostram-se importantes de ressaltar. Usualmente se atualiza a noção de que o trabalho com PCD é formado por ações de tutela, e que se supõe uma noção de dependência para com um(a) responsável. Entretanto, compreendeu-se que o grupo, diante de uma proposta não verticalizada e hierárquica, compôs uma parceria com a pesquisadora e pode desenvolver, diante dessa confiança atribuída ao grupo de estudantes, um trabalho produtivo. De outra forma, vê-se que o campo do Turismo, como estratégico em termos de produção de saúde mental e bem-estar social, precisa investir na formação de pessoas (na valorização de patrimônio e das formas de ocupação de espaços públicos), o que demanda questionar qual a noção de cidadania e inclusão que o estado da arte em Turismo reafirma.

Especialmente no que concerne à compreensão da cidadania como, também, à ocupação política da cidade (direito historicamente negado para pessoas com deficiência), é importante ressaltar que o Livro Sensorial - enquanto disparador educativo - pode ser modelado conforme diferentes conjunturas ambientais (exigindo, evidentemente, um estudo prévio das potencialidades e limitações destas). A elaboração do trabalho com o Livro em espaços de cuidado psicossocial já instituídos, como: na RAPS - Rede de Atenção Psicossocial, o que demanda compreender como o Turismo se aproxima destes locais destinados a promoção e prevenção em saúde mental; em museus e outras organizações culturais (o que possibilita discussões intensas sobre acessibilidade); em ações recreativas e de apoio psicopedagógico; entre outros.

Ressaltando uma limitação do presente estudo, indica-se que a possibilidade de revisão de literatura internacional de modo a verificar como se dá a discussão com as PCD no estado da arte em Turismo, pois muito pouco ou quase nada foi encontrado no panorama brasileiro. De outra forma, e em termos gerais, percebe-se que o presente estudo espelha uma tendência importante no foco do Turismo: teoricamente, demanda continuar dilatando as possibilidades deste como dispositivo de emancipação humana e cidadã; e, em termos práticos, a exigência de um alargamento das técnicas de trabalho para realizar atividades com impacto social micropolítico. 
Assim, foi possível verificar que ações micropolíticas educacionais podem contribuir e multiplicar processos de inclusão, desenvolvimento de subjetividades mais equânimes e exercício da cidadania, permitindo a construção de um espaço comum, contradizendo racionalidades excludentes e ampliando a atuação de profissionais de Turismo para além do que poderia ser considerado como "senso comum" de desempenho. Sendo assim, por intermédio de ações que envolvam, por exemplo, Lazer e Patrimônio, o Turismo apresenta suas múltiplas interfaces quando oferece a possibilidade de atividades lúdicas não convencionais, nesse casso a construção do Livro Sensorial, que se encontram representadas de forma a contribuir para o desenvolvimento e inclusão com pessoas historicamente excluídas.

\section{Referências}

BRZEZINSKI, I.; SANTOS, C. A. Sentido e significados da política: ação e liberdade. Brasília: LiberLivro, 2015.

CAMARGO, E. P. Inclusão social, educação inclusiva e educação especial: enlaces e desenlaces. Ciência \& Educação, Bauru, v. 3, n. 1, p. 1-6, mar. 2017. Disponível em: http://www.scielo.br/pdf/ciedu/v23n1/1516-7313-ciedu-23-01-0001.pdf. Acesso em: 3 jun. 2019.

CORIOLANO, L. N. M. T. Epistemologia da análise do discurso no turismo. Caderno Virtual de Turismo, Rio de Janeiro, v. 5, n. 2, p. 50-56, jan. 2005. Disponível em:

http://www.ivt.coppe.ufrj.br/caderno/index.php/caderno/article/view/85. Acesso em: 6 maio 2019.

DE MARCO, M. A. Do modelo biomédico ao modelo biopsicossocial: um projeto de educação permanente. Revista Brasileira de Educação Médica, Rio de Janeiro, v. 30, n. 1, p.60-72, abr. 2006. Disponível em: http://www.scielo.br/scielo.php?pid=S0100-

55022006000100010\&script=sci_abstract\&tlng=pt. Acesso em: 5 jul. 2019.

DE MASI, D. O ócio criativo. 3. Ed. Rio de Janeiro: Sextante, 2000. 212 p.

DOMINGUES, I. (Org.). Conhecimento e transdisciplinaridade. Belo Horizonte: Editora UFMG, $2001.72 \mathrm{p}$.

ELO7. Livro sensorial. 2018. Disponível em: https://www.elo7.com.br/lista/livrosensorial? sortBy=3\&city=\&searchFilter=. Acesso em 6 maio 2018.

FELTRO, Escola de. Livro sensorial em feltro: inspire-se e faça em casa. [2019]. Disponível em: https://www.escoladefeltro.com.br/livro-sensorial-em-feltro/. Acesso em: 6 maio 2019.

FOUCAULT, M. A arqueologia do saber. 7. Ed. Rio de Janeiro: Forense Universitária, 2008. 244 p.

FOUCAULT, M. A hermenêutica do sujeito: curso dado no College de France (1981-1982). 2. ed. São Paulo: Martins Fontes, 2006. 352 p.

FOUCAUlt, M. Vigiar e Punir. Petrópolis: Vozes, 1987. 288 p. 
GUATTARI, F.; ROLNIK, S. Micropolítica: cartografías del deseo. Madrid: Traficantes de Sueños, 2006. $328 \mathrm{p}$.

LIMA, M. E.; JUNIOR, A. S. M.; BZEZINSKI, I. Cidadania: sentidos e significados. CONGRESSO NACIONAL DE EDUCAÇÃO (EDUCERE), 13., 2017, Curitiba, Anais [...]. Curitiba: Pontifícia Universidade Católica do Paraná, 2017. p. 2481-2494. Tema: formação de professores: contextos, sentidos e práticas. Disponível em: https://educere.bruc.com.br/arquivo/pdf2017/24065_12317.pdf Acesso em: 03 jun. 2019.

MAIS, Pause. Livro sensorial: você já ouviu falar no livro de brincar? 2018. Disponível em: http://pausemais.com.br/livro-sensorial-voce-ja-ouviu-falar-no-livro-de-brincar/. Acesso em: 6 maio 2019.

MANTOAN, M. T. É. O direito de ser, sendo diferente na escola. Revista CEJ, Brasília, n. 26, p. 3644, 2004. Disponível em: http://www.cjf.jus.br/ojs2/index.php/revcej/article/view/622. Acesso em: 03 jun. 2019.

MASCARENHAS, F. Lazer e utopia: limites e possibilidades de ação política. Movimento, Porto Alegre, v. 11, n. 3, p.155-182, jul. 2005. Disponível em:

https://www.redalyc.org/pdf/1153/115315216009.pdf. Acesso em: 11 maio 2019.

MASCARENHAS, F. O pedaço sitiado: cidade, cultura e lazer em tempos de globalização. Revista Brasileira de Ciências do Esporte, Campinas, v. 24, n. 3, p. 121-143, maio 2003. Disponível em: http://revista.cbce.org.br/index.php/RBCE/article/view/767/441. Acesso em: 11 maio 2019.

MATOS, D. U. A Produção do Sujeito Universal na Educação. 2013. 104 f. Dissertação (Mestrado) - Curso de Ciências Humanas e Sociais, Mestrado em Educação, Universidade Federal de Ouro Preto Ufop, Ouro Preto, 2013. Disponível em:

https://www.repositorio.ufop.br/bitstream/123456789/3292/1/DISSERTA\%C3\%87\%C3\%83O_Produ \%C3\%A7\%C3\%A3oSujeitoUniversal.pdf. Acesso em: 8 abr. 2019.

MATTOS, C. L. G. A abordagem etnográfica na investigação científica. In: MATTOS, Carmen Lúcia Guimarães de. Etnografia e educação: conceitos e usos. Campina Grande: Eduepb, 2011. p. 49-83. Disponível em: http://books.scielo.org/id/8fcfr/pdf/mattos-9788578791902-03.pdf. Acesso em: 28 abr. 2019.

MERCADO LIVRE. Livro sensorial. 2018. Disponível em: https://livros.mercadolivre.com.br/infanto-juvenis/livro-sensorial_PriceRange_200-0. Acesso em: 6 maio 2019.

MOREIRA, J. C. Geoturismo: uma abordagem histórico-conceitual. Turismo e Paisagens Cársticas, Campinas, v. 3, n. 1, p.5-10, jun. 2010. Disponível em:

http://www.cavernas.org.br/ptpc/tpc_v3_n1.pdf\#page=7. Acesso em: 6 maio 2019.

MTUR. Ministério do Turismo. Cartilha dicas para atender bem turistas idosos. 2016a. Elaborada por Ministério do Turismo. Disponível em:

http://www.turismo.gov.br/images/pdf/27_09_2016_cartilha_idoso.pdf. Acesso em: 5 maio 2019.

Observatório de Inovação do Turismo - Revista Acadêmica

Vol. XV, $\mathrm{n}^{\circ} 1$, abril - 2021 
MTUR. Ministério do Turismo. Jovens viajantes impulsionam o turismo brasileiro. $2016 \mathrm{~b}$. Disponível em: http://www.turismo.gov.br/\%C3\%BAltimas-not\%C3\%ADcias/5926-jovens-viajantesimpulsionam-o-turismo-brasileiro.html. Acesso em: 5 maio 2019.

MTUR. Ministério do Turismo. Plano Nacional de Turismo 2018-2022: PNT em Ação. 2018. Disponível em: http://www.turismo.gov.br/acesso-a-informacao/11735-pnt-ema\%C3\%A7\%C3\%A3o.html. Acesso em: 27 abr. 2019.

MTUR. Ministério do Turismo. Turismo discute diretrizes para público LGBT, idoso e com deficiência. 2017. Disponível em: http://www.turismo.gov.br/\%C3\%BAltimasnot\%C3\%ADcias/8215-turismo-ir\%C3\%A1-priorizar-a\%C3\%A7\%C3\%B5es-para-p\%C3\%BAblicolgbt,-idoso-e-com-defici\%C3\%AAncia.html. Acesso em: 5 maio 2019.

OCHOA, M. F. Livros sensoriais e cinestésicos: experimentando a arte através dos cinco sentidos e da falta deles. 2015. 96 f. TCC (Graduação) - Curso de Licenciatura em Artes Visuais, Departamento de Artes Visuais, Universidade Federal do Rio Grande do Sul, Porto Alegre, 2015. Disponível em: https://www.lume.ufrgs.br/bitstream/handle/10183/134691/000987302.pdf?sequence=1. Acesso em: 6 maio 2019.

PENA, R. F. A. Transportes na era da globalização. Publicado por Mundo Educação. 2018. Disponível em: https://mundoeducacao.bol.uol.com.br/geografia/transportes-na-era-globalizacao.htm. Acesso em: 5 maio 2019.

ROCHA, M. L.; AGUIAR, K. F. Pesquisa-Intervenção e a produção de novas análises. Psicologia Ciência e Profissão, [S. 1.], v. 23, n. 4, p. 64-63. 2003. Disponível em: http://pepsic.bvsalud.org/pdf/pcp/v23n4/v23n4a10.pdf. Acesso em: 08 abr. 2019.

SAÚDE, Terra. Livro sensorial ajuda a exercitar a coordenação motora. 2015. Disponível em: https://fortissima.com.br/2015/12/03/livro-sensorial-ajuda-exercitar-coordenacao-motora-14748643/. Acesso em: 6 maio 2019.

SAVIANI, D. Ética, educação e cidadania. Revista n ${ }^{\circ}$ 15. 2013. Disponível em: https://docplayer.com.br/5427383-Etica-educacao-e-cidadania-dermeval-saviani-revista-no-15.html. Acesso em: 6 maio 2019.

SEBRAE - Serviço Brasileiro de Apoio às Micro e Pequenas Empresas. Planejamento de Marketing: conhecer o público alvo e planejar em conjunto potencializa estratégias de marketing. 2017. Disponível em: https://sebraers.com.br/turismo/conhecer-o-publico-alvo-e-planejar-emconjunto-potencializa-estrategias-de-marketing/Rua Coronel Augusto Carvalho. Acesso em: 6 maio 2019.

SEBRAE - Serviço Brasileiro de Apoio às Micro e Pequenas Empresas; CNTUR - Confederação Nacional do Turismo. Pesquisa: perfil do turista e dos segmentos de oferta. 2012. Disponível em: http://www.bibliotecas.sebrae.com.br/chronus/ARQUIVOS_CHRONUS/bds/bds.nsf/E4EE72775D0F 632A83257A0C00757D41/\$File/NT00047646.pdf. Acesso em: 11 maio 2019.

SOARES, F. M. A produção de subjetividades no contexto do capitalismo contemporâneo: Guattari e Negri. Fractal: Revista de Psicologia, Rio de Janeiro, v. 28, n. 1, p.118-126, jan. 2016. Disponível em: http://www.scielo.br/pdf/fractal/v28n1/1984-0292-fractal-28-1-0118.pdf. Acesso em: 3 jun. 2019.

Observatório de Inovação do Turismo - Revista Acadêmica

Vol. XV, $\mathrm{n}^{\circ} 1$, abril - 2021 